\title{
COUNTRY PROFILE \\ Developing a capacity-building programme to support a mental health service modernisation pilot project in Lviv region of Western Ukraine
}

\author{
Tracey Power ${ }^{1} \odot$ and Orest Suvalo ${ }^{2}$
}

${ }^{1} \mathrm{MA}$, Management of Community Care, Managing Director, Implemental Worldwide UK. Email: tracey.power@kcl.ac.uk ${ }^{2} \mathrm{MD}$, Psychiatrist, Coordinator of Community-Based Mental Health Services Development, Mental Health for Ukraine Project. Ukraine

Keywords. Low- and middleincome countries; capacity-building; implementation.

First received 19 Aug 2019 Final revision 4 Mar 2020 Accepted 21 Apr 2020

\section{doi:10.1192/bji.2020.23}

(c) The Authors 2020. This is an Open Access article, distributed under the terms of the Creative Commons Attribution-

NonCommercial-ShareAlike licence (http://creativecommons. org/licenses/by-nc-sa/4.0/), which permits non-commercial re-use, distribution, and reproduction in any medium, provided the same any medium, provided the same Commons licence is included and the original work is properly cited. The written permission of Cambridge University Press must be obtained for commercial re-use.
This paper reflects on the development of a capacity-building programme to support a mental health service modernisation pilot project based in the Lviv region of Western Ukraine. National programmes that aim to modernise mental health services now have the experience of other countries on which to draw. The challenges faced by such modernisers have much in common. Nevertheless, although there are lessons to be learned from what has worked well elsewhere, we caution that the local context can have a profound effect on the successful implementation of plans based on best practice.

Ukraine is currently carrying out a significant reform of its healthcare services. Reorganisation of the mental health system is one of the key components. Overarching aims include improving access to and availability of evidence-based care, developing and delivering modern health workforce plans, and enhancing transparency and accountability in the system.

The government is committed to making changes to both the structure of the health system and how providers are funded. Primary care developments based on the principle of 'funding following the patient' are promising. Legislative change is underway; a concept note on mental healthcare development was approved in $2017^{1}$ and a draft action plan for the reform of the mental health system was produced. The social care system has also been subject to review, with the aim of shifting mental healthcare into community-based services.

The proposed changes to the mental health system will see the introduction of a defined package of care options, in which the patient will have a choice about where to be treated. Hospital providers will become 'communal non- commercial enterprises' (similar to National Health Service foundation trusts in the UK) with the freedom and flexibility to operate with more autonomy. The proposed reforms will also encourage a multiplicity of new providers (such as not-for-profit non-governmental organisations and private providers) to improve patient choice, care quality and outcomes.

\section{Delivery challenges}

The challenges to delivering these aspirations are many. ${ }^{2}$ Gaining independence from the Soviet Union in 1991 led to economic growth until Ukraine faced political turbulence and conflict in the East (including the annexation of Crimea by Russia in 2014) and occupation of two Eastern regions. Economic challenges led to a significant reduction in the national health budget. Continuing political turbulence has had an influence on both the development of policy and implementation plans.

Until recently, Ukraine operated a centralised model of healthcare that did not address the needs of its diverse population. In common with many other Eastern European countries, reforms must take into account an ageing population, rapid urbanisation and the expanding adoption of an unhealthy lifestyle. However, an additional challenge for Ukraine is the war in the East. There are 1.5 million officially registered internally displaced persons who lack access to basic services, including healthcare and psychosocial support. ${ }^{3,4}$ There is therefore a pressing need to develop regional plans and local approaches to models of care and support.

Risk factors for poor mental health are present across Ukraine, including relatively high levels of poverty and unemployment, which militate against the affordability of care and medical treatment. There are additional risks associated with the conflict in the East. Stigma associated with mental health problems is profound in this culture and has been compounded by a lack of trust in state institutions. There have been no systematically organised information campaigns to promote public awareness of mental health issues.

Against this backdrop, there are also a significant number of international organisations working in Ukraine to share knowledge and expertise. These include a review carried out by the World Bank in 2017; $;^{5}$ the support of the World Health Organization (WHO) for a local adaptation of the mhGAP Intervention Guide ${ }^{6}$ and the mhGAP Humanitarian Intervention Guide $;^{7}$ the work of the 
International Medical Corps with conflict-affected communities; ${ }^{8}$ and the Human Rights in Mental Health - FGIP federation, which has been supporting deinstitutionalisation and the provision of social care homes. ${ }^{9}$ The WHO Europe policy of $2007^{10}$ and the Geneva initiative of $1980^{11}$ have also been taken into consideration. A major challenge for the government of Ukraine is how to coordinate efforts across myriad partners, especially in the East; a further challenge is how to ensure, given the constraints on government funding for health and social care, that these efforts are sustainable with stable state support.

\section{Mental Health for Ukraine pilot project}

The Mental Health for Ukraine (MH4U) project is financed by the Swiss Agency for Development and Cooperation. The commission for the implementation of the project, following a competitive tender, was assigned to a consortium, led by GFA Consulting Group GmbH, together with their international partners. These include Implemental Worldwide CIC (previously Maudsley International), the Zurich University Hospital of Psychiatry and the Ukrainian Catholic University of Lviv. The aims of the consortium are to support policy makers, healthcare professionals, and people who live with mental health problems and their families, and to build a mental health system that is more available and accessible, providing better quality of care and supporting people in the community. Prior to the MH4U programme there was an inception' phase. This identified priorities for capacitybuilding by government agencies which could complement and link with those funded and delivered by other international partners. The aim was to identify best practice and opportunities to build on existing local innovations.

\section{Views of stakeholders}

The issues and concerns raised with the MH4U team would be common to many, if not most, mental health system reforms. They include the following needs: to identify governmental funding; to implement decentralisation and local planning; to coordinate and integrate care across organisational boundaries; and to integrate health and social care. Models of care should be based on evidence of best practice and should recognise the needs of vulnerable groups, especially children and young people and the ageing population. Patients and carers should be empowered. There is a need for leadership and strengthening of the mental health workforce.

There were also important considerations to take into account concerning the cultural context of post-totalitarian Ukrainian society. A pervasive legacy of Soviet era rule is a general feeling of disempowerment, which manifests in an unwillingness to take the initiative and accept responsibility for finding local solutions 'outside' established practice. Unfortunately, this attitude is compounded by the fact that professionals have had little experience of team and multidisciplinary working in the public sector; previously, the emphasis was on individual accountability. There has been insufficient development of professional roles. Nurses have been working as basic carers, and doctors tend to choose personally preferred interventions. Practitioners tend to work in organisational silos, and there are few examples of stakeholder involvement in service planning. Patients and their families are not consulted, and there are high levels of stigma. There are also tensions between the government and professional bodies and within government, between health and social care.

\section{Implementation}

Moving forward into the implementation of the pilot phase, there is to be an emphasis on leadership training to support the implementation of legislative changes. There should be practical examples of multisector collaboration and interdisciplinary team working. $\mathrm{MH} 4 \mathrm{U}$ will facilitate the development of local implementation teams and provide capacity-building for family doctors (via mhGAP). There will be a small grant programme and support for the new Center for Mental Health, as well as for reforms to legislation, accrediting providers and coordinating stakeholders. A communication campaign has begun to address the deeply engrained cultural stigma about mental health disorders. The project will prioritise developments for children, young people and their families, where an integrated approach to service delivery is crucial for early intervention and preventative approaches.

Genuinely respectful relationships among collaborators that are nurtured over time will be necessary, but success can be achieved, as has been demonstrated by an earlier project in Sverdlovosk oblast. ${ }^{12}$ Assessing the success of the pilot activities will be the first step before widening the scope of capacity-building support across the country. The process we have described has relevance for similar mental health developments in other parts of the world.

\section{Acknowledgements}

We thank the MH4U team members who collectively reflected on their experiences during the project inception phase and identified the themes described in this paper, and the Swiss Agency for Development and Cooperation for their support for and input into this project.

\section{Author contributions}

The authors are both involved in the development and delivery of the $\mathrm{MH} 4 \mathrm{U}$ project. They jointly drafted, reviewed and amended the paper.

\section{Declaration of interest}

The authors are members of the Mental Health 4 Ukraine (MH4U) project team. The Mental Health for Ukraine (MH4U) project is financed by the Swiss Agency for Development and Cooperation, to assist the Ukrainian government with their proposed mental health care developments. It is run by a 
consortium, led by GFA Consulting Group $\mathrm{GmbH}$, together with their international partners Implemental Worldwide CIC, the University Hospital of Psychiatry Zurich and the national implementing partner the Ukrainian Catholic University of Lviv.

ICMJE forms are in the supplementary material, available online at https://doi.org/10.1192/bji.2020.23.

\section{References}

1 Cabinet of Ministers of Ukraine. Health Care System Reform. Cabinet of Ministers of Ukraine, 2019 (https://www.kmu.gov.ua/ en/reformi/rozvitok-lyudskogo-kapitalu/ reforma-sistemi-ohoroni-zdorovya)

2 Cabinet of Ministers of Ukraine. Kontseptsiia rozvytku okhorony psykhichnoho zdorovia v Ukraini na period do 2030 roku [Mental Health Care Development Concept Note in Ukraine for the period up to 2030]. Cabinet of Ministers of Ukraine, 2017 (https://zakon3.rada.gov.ua/laws/show/1018-2017-p).

3 Romaniuk P, Semigina T. Ukrainian health care system and its chances for successful transition from Soviet legacies. Global Health 2018; 14: 116.

4 Kuznestsova I, Mikheieva O, Catling J, Round J, Babenko S. The Mental Health of Internally Displaced People and the General Population in Ukraine. University of Birmingham and Ukrainian Catholic University 2019 (https://www.humanitarianresponse. info/sites/www.humanitarianresponse.info/files/documents/files/ mental_health_of_idps_and_general_population_in_ukraine. pdf).

5 Weissbecker I, Khan O, Kondakova N, Poole LA, Cohen JT. Mental health in transition: assessment and guidance for strengthening integration of mental health into primary health care and community-based service platforms in Ukraine (English). Global Mental Health Initiative, World Bank Group, 2017.
6 World Health Organization. mhGAP Intervention Guide Mental Health Gap Action Programme Version 2.0 for mental, neurological and substance use disorders in non-specialized health settings. WHO, 2016.

7 World Health Organization and United Nations High Commissioner for Refugees. mhGAP Humanitarian Intervention Guide (mhGAP-HIG): Clinical Management of Mental, Neurological and Substance Use Conditions in Humanitarian Emergencies. WHO, 2015.

8 International Medical Corps. Improving Mental Health and Psychosocial Support (MHPSS) for Conflict Affected Populations in Eastern Ukraine through Increased Capacity for Psychosocial Support Activities and Services Aligned with IASC Guidelines among National Actors, Organizations and Agencies. IMC, 2019.

9 Federation Global Initiative on Psychiatry and the Ministry of Social Affairs of Ukraine. Transforming Social Care Homes in Ukraine. Proposals Regarding the Slavyansk and Svyatoshinsky Social Care Homes. FGIP, 2018 (https://www.gip-global.org/files/ ss-fin-eng.pdf).

10 Knapp M, McDaid D, Mossialos E, Thornicroft G. Mental Health Policy and Practice across Europe: the Future Direction of Mental Health Care. World Health Organization, Regional Office for Europe, 2007

11 Birley J. The Geneva initiative on psychiatry. Eur Psychiatry 1998; 13: 165

12 Jenkins R, Lancashire S, McDaid D, Samyshkin Y, Green S, Watkins J, et al Mental health reform in the Russian Federation: an integrated approach to achieve social inclusion and recovery. Bull World Health Organ 2007; 85: 858-66.

\title{
SPECIAL PAPER \\ Psychiatry in the federal correctional system in Canada
}

\author{
Colin Cameron, ${ }^{1}$ Najat Khalifa, ${ }^{2}$ Andrew Bickle, ${ }^{3} \odot$ Hira Safdar ${ }^{4}$ and \\ Tariq $\operatorname{Hassan}^{5} \odot$
}

${ }^{1}$ Correctional Service Canada/ Government of Canada, FRCPC, National Senior Psychiatrist, Ottawa, Ontario, Canada

${ }^{2} \mathrm{MD}$, Associate Professor in Forensic Psychiatry, Queen's University Department of Psychiatry, Providence Care Hospital, Kingston, Ontario, Canada

${ }^{3}$ MRCPsych, Assistant Professor in Forensic Psychiatry, Queen's University Department of Psychiatry, Providence Care Hospital Kingston, Ontario, Ontario, Canada

${ }^{4}$ MBBS, Assistant Professor, Victoria Hospital, London Health Sciences Centre, London, Ontario, Canada

${ }^{5}$ FRCPC (Forensic Psychiatry), Divisional Chair and Clinical Director, Queen's University Department of Psychiatry, Department of Psychiatry, Krovidence Care Hospital, hassant@providencecare.ca
The unique challenges of the correctional healthcare environment are well-documented. Access to community-equivalent care, voluntary informed consent of offenders with mental disorder, violence risk, suicide risk, medication misuse, and clinical seclusion, confinement and segregation are just $a$ few of the challenges faced by correctional psychiatric services. This paper shares experiences for dealing with the ongoing challenges for psychiatrists working in the field. It provides an overview of the current state of mental healthcare in the federal correctional system in Canada, the legislative framework and initiatives aimed at addressing the healthcare needs of federal inmates.

Correctional psychiatry is increasingly recognised as a subspecialty of forensic psychiatry, given the unique challenges of the prison healthcare environment. Criticisms abound about the apparent dual loyalties of correctional psychiatrists for both patient care and public safety. Access to community-equivalent care, voluntary informed consent of offenders with mental illness, violence and suicide risk, medication misuse and diversion, and clinical seclusion and restricted movement are just a few of the hot-button issues faced daily by correctional psychiatrists. ${ }^{1,2}$

Indeed, as in other jurisdictions, Correctional Service Canada (CSC) has come under increased scrutiny by prison advocacy groups and human rights lawyers. For example, there have been several litigations in recent years that have driven a number of reforms to the federal correctional system, including health services, many of which are outlined in this paper. Among these was the December 2017 decision by the Ontario Superior Court in Corporation of the Canadian 